\title{
Cinematic virtual reality: Towards the spatialized screenplay
}

Miriam Ross, Victoria University of Wellington

Alex Munt, University of Technology Sydney

\begin{abstract}
This article considers how screenwriting might operate in the newly established medium of cinematic virtual reality $(C V R)$. In Part One, we take a wide view of ways to consider screenwriting and development for CVR. Our approach theorizes CVR in the tradition of picture-making (or image-making) practices that can be traced within a broader history of the visual arts - from painting, to photography and contemporary art. In this way, we lay open the possibility for CVR to find diverse paths as it responds to narrative concerns rather than suggest it should merely repeat the consolidation of narrative that occurred with the transition of exploratory early cinema to the dominant Classical Hollywood system. In Part Two, our case study approach considers co-author, Miriam Ross', CVR practice-based research to allow a discussion of the format that can be used for delivery of the CVR screenplay. Our aims are to connect a historically based spatialization of the image with the question of the spatialization of the screenplay for CVR 360-degrees media. The agenda is to expand the conversation around CVR to reflect upon, and inspire, new ways of thinking (and seeing) the potential for the development of screen ideas in this medium.
\end{abstract}

\section{Keywords}




\section{CINEMATIC VIRTUAL REALITY VR 360 MEDIA IMMERSIVE SCREENWRITING}

\section{Cinematic virtual reality}

Cinematic virtual reality, or 'CVR' for short, is an immersive virtual reality experience 'where individual users can look around synthetic words in 360, often with stereoscopic views, and hear spatialized audio specifically designed to reinforce the veracity of the virtual environment' (Mateer 2017: 15). This is also referred to as 'Film VR' or 'Live Action VR', with reference to its status as a lens-based cinematographic moving image practice, and contrasting 'Traditional VR' as computer generated virtual world more akin to interactive gaming engines. The head mounted display apparatus is the site of convergence for these two models, allowing viewers to accept both under the umbrella of VR. In CVR, the 'cinematic' prefix further reflects the ability to capture increasingly high-resolution images, from $2 \mathrm{~K}$, to $4 \mathrm{~K}$ and now $8 \mathrm{~K}$, consistent with trends in digital filmmaking. The cinematic prefix also suggests the question of dramatic narrative for the emerging media. Consistent with early (celluloid) cinema over a century earlier (Gunning 1990; Turvey 2004), initial VR live-action projects have centred on documentary (actualities) and/or spectacular iterations of experience - travelling into outer space (Access Mars, 2017); living with dinosaurs (VR Dinos, 2015) or swimming with sharks (Shark Dive VR, 2016) - and have maintained a short duration of seven to ten minutes. Less clear is whether CVR will develop narrative akin to the Classical style that emerged in the United States and influenced international filmmaking (Bordwell et al. 1985) or whether it will take different paths in response to its proximity to other forms, particularly gaming. 
Globally the CVR space is one attracting both money and filmmaking talent with established directors being wooed by commercial interests. This includes Kathryn Bigelow (The Protectors 2016), Doug Liman (Invisible 2017) and Alejandro Gonzalez Iñarritu, who launched his Carne y Arena (Flesh \& Sand) at Cannes 2017. Its debut at the most prestigious film festival suggests the new medium is being taken seriously but that it is also closely tied to existing cinematic practice. In her article, Storytelling with virtual reality in 360 degrees: A new screen grammar, Kath Dooley provides a case-study of recent Australian virtual reality works including VR Noir (2016), Collisions (2016) and The Next Striker (2017: 165). As the title of Dooley's article suggests, most attention in the CVR discourse operates at the level of the remediation of production-based filmmaking, utilizing directing, cinematography, picture editing or sound design for spatialized media. The question of the screenplay, its form and function, within this rapidly progressing field has, however been overlooked by the genuine excitement, and novelty, of a new digital model of audio-visual production. Here there are, again, parallels with the development of early cinema when the pace of film production outstripped consideration of the screenplay in the process. Steven Maras provides the historical context, where the '[...] absence of the script, plays a defining role' (2009: 37). For CVR, work on the theorization of the screenplay is in its infancy. There have been suggestions for formats that deal with the interactive possibilities provided in traditional VR (Cavazza 2007) but less consideration for the emerging CVR. Preliminary attempts arrive replete with screenwriting guru-esque assertions of the primacy of 'story', and 'storytelling', as the holy grail (Millard 2006; Bucher 2017; Tricart 2017). Aristotle is cited, of course. In her survey Dooley reports back that CVR demands 'a good story' 
(Grambart 2015 in Dooley 2017: 165) and a necessity to create a 'core experience'

(Jerald 2015: 229 in Dooley 2017: 167) for an audience helmed by 'one good idea rather than several ideas' (Jerald 2015: 268 in Dooley 2017: 167). Dooley notes the need for more work towards 'the physical format of the VR screenplay' in CVR research (2017: 170) and this article aims to account for that gap.

\section{Regimes of vision}

To produce CVR the apparatus consists of an omnidirectional camera rig fitted with multiple cameras or a single camera with multiple lenses. The cameras typically utilize ultra-wide or 'fisheye', curved lenses which, when combined, expand the field of view to capture an environment in 360 degrees. Typically, the fixed camera(s) takes the place of the idealized viewer to capture multiple images which require post-production 'stitching' to map together into a 'flattened' panoramic image that can be reconstituted as a spherical field of view in the headset, or for viewing on a flat screen by moving the cursor. The stitch is often evident at the point of overlap between images, creating a digital artefact where the environment does not precisely align and hinting at CVR's representation rather than replication mode.

With this understanding - whilst the CVR 'experience' trades on the viewer's perception of a holistic 360-degree environment - it remains a spatial illusion generated from two-dimensional image(s). This illusory capacity of CVR has a rich media archaeology, from still stereoscopic images and magic lantern slides to Georges Méliès’ magician-inflected filmmaking, the development of deep-focus cinematography and the 
history, and resurgence, of immersive stereoscopic (3D) cinema. In this context, it is significant to embrace the ontological status of CVR as an image, and one that embodies a particular regime of vision. Understanding it in this way allows consideration of how the CVR screenwriting process might function to move beyond close adherence to cinematic practice and towards an expanded sense of the moving 'picture'.

CVR relies on a regime of vision that re-orientates the optics in emerging media to earlier periods and challenges the dominance of linear perspective which has defined the screen arts in the last century. In A History of Pictures: From the Cave to the Computer Screen, David Hockney, with art historian Martin Gayford, define pictures as 'representations of the three-dimensional world on flat surfaces such as canvas, paper, cinema screens and smartphones' (2014: 7). It is an account of the historical 'interactions' between different iterations of the picture, whether generated in paint, photography or film:

In the past, again and again developments in media, techniques and equipment have altered the manner in which pictures are made, and also the ways that they have been seen. They moved from the cave wall, to the temple, to the church, the photograph album, the cinema, television and the computer screen. (Hockney and Gayford 2014: 337)

David Hockney compares a frame from Taxi Driver (1976) with one of his own paintings, Santa Monica Blvd (1978-80). He suggests Martin Scorsese's shallow, or 'flat', perspective for his establishing-shots of New York City streets has a clear 
correspondence to the 'Hockney angle' in his pop-art aesthetic work at the time (Hockney and Gayford 2014: 331). A History of Pictures probes 'how we see, and what we see' (Hockney and Gayford 2014: 341) - and whilst the historical sweep leaves little room for a discussion of convergent digital media, this approach can certainly be applied towards consideration of CVR as another typology of moving picture. In particular, it leaves space to consider CVR beyond the deep, perspectival, mode of vision that dominates cinema and other flat screen media.

The discovery of linear perspective by Filippo Brunelleschi, in the early fifteenth century, marked the beginning of a 'long dialogue between pictures and optics' (Hockney and Gayford 2014: 98). For Gayford, Brunelleschi's painting of the Florentine Baptistery 'was the first known picture in history that was intended not to depict a person, deity, story, event or object, but to demonstrate an optical truth' and led to the inception of photography some four centuries later (Hockney and Gayford 2014: 96). Given the lensbased cinematographic production of CVR this medium participates within this pictorial interaction. Yet, whilst CVR shares the ambitions of painting, photography and cinema before (the pursuit to represent three-dimensional space upon a two-dimensional surface) its resultant spherical view destabilizes the exterior, beyond-the-frame, viewing position provided by traditional perspective (Panofsky 1991).

Leon Battista Alberti's theorization of perspective in De pictura (1404-72) formalized the dominant paradigm for a picture today as 'a window on the world' (Sinisgalli 2011). This appears, literally, in Albrecht Durer's woodcut Draughtsman Making a Perspective Drawing of a Reclining Woman (1525), replete with the overarching male gaze at work. In contrast, 360-degree virtual reality media offers a 
significant departure towards the absolution of the frame (or 'window') altogether. This erasure of the primary western historical device for the arrangement of bodies, and objects, in space needs to be reckoned with. For Kath Dooley, '360-degree projects have no screen edge: the world of the project surrounds the viewer' (2017: 164). In early CVR research this friction has been described as 'Circle Versus Square' and, with the recalibration towards a new optical paradigm, offers an opportunity to (re)consider the dominant cinematic gaze from a political, cultural or feminist perspective (Syed 2017).

Figure 1: Tommaso Masaccio, The Tribute Money, 1425. Fresco 247 x 597cm. Brancacci Chapel, Santa Maria del Carmine, Florence. Courtesy of Florentine Civic Museums.

This does not necessitate an entire disruption to the visual regime of the lens but, rather, drawing on historical approaches points to the way divergences from the norm may occur. The Tribute Money (1425), by Tommaso Masaccio, is a Renaissance fresco at the Brancacci Chapel, which reveals ways in which the spatiality of the image can be advanced. The painting depicts a scene from the Gospel of Matthew when Jesus arrives in Capernaum with his Apostles. Jesus stands in the centre of semi-circular configuration of men. A single-point linear perspective is generated from the receding architectural lines of the colonnade to the right - drawing the eye to Jesus as the central figure among a semi-circular arrangement of men (Lowis and Pickeral 2016: 17). The tax collector requests the tribute and Jesus instructs St Peter how to proceed. The work proved innovative in its representation of both space and time: since it presents a narrative in 
three independent scenes featuring the same characters. To the left, St Peter gathers a coin from the mouth of a fish he has pulled from the Sea of Galilee (as instructed by Jesus) and on the right he pays the 'tribute' and closes the deal with the tax collector with a handshake. The advanced spatiality of the image in this painting is also reflected in near 360-degree depictions of the figures and the multiple instalments of the narrative allow the tax collector and St Peter to be represented in three dimensions (Paoletti and Radke 1997: 230). The figures are portrayed in a 'long-shot' and the semi-circular geometry, the perspectival optics, and detailed painterly work on the colour and textures of the men's robes produce an immersive work. Whilst this Renaissance picture still obeys the rules of linear perspective it challenges the 'window on the world' paradigm through its formal and narrative organization - suggestive of a scene the viewer can almost step inside of. The 'new' challenge for CVR screenwriting is to think about how narrative can occur across space, as moving image media and how it can draw on a wider historical analysis of the ways in which visual art has dealt with questions of scale, form, geometry, optics and narrative prior.

Figure 2: Jan Van Eyck, The Madonna with Canon van der Paele, 1436. Oil on wood 122 x 157cm. Groeningemuseum, Bruges. Musea Brugge (c) www.lukasweb.be - Art in Flanders vzw, photo Hugo Maertens.

This leads to another example of the spatialized image in art history, which can be located in the early Renaissance painting by Jan Van Eyck: The Madonna with Canon van der Paele (1436). This is a picture highlighted as significant by Gayford and 
Hockney (2014: 103) for the way it situates Christian saints within the mortal pictorial space of Joris van der Paele - the wealthy clergyman who commissioned the work in a period of ill-health. In formal terms the painting adopts a similar spatial tactic to Masaccio's The Tribute Money staging the Madonna and child in the centre of a semicircular arrangement of figures revealed in full-length. The colours and folds of their robes are rendered in intricate detail. Once again, the viewer is invited to 'step-inside' a holy circle. This pictorialism syncs with the contemporary notion of the idealized viewer located in the centre of the spherical 360-degrees CVR image. For David Hockney this picture defies notions of linear perspective to produce a regime of vision closer to reality:

Van Eyck didn't use linear perspective; he used multiple points of view. In his pictures you feel you are close to everything, even the distant faces in the crowd. I think that is because actually he was close when he was drawing them. You are looking not through one window, but through many, which is nearer to the way we actually see. (Hockney and Gayford 2014: 104, original emphasis)

However, Hockney also adds 'the figures are too big for the architecture', an observation that concurs with the representation of figures in CVR projects, which appear distorted (aggrandized) within their environment due to the optics of the fish-eye lens; yet is downplayed by industry expectations that CVR should offer greater fidelity to the world around us. As Hockney reminds us, in the Middle Ages the Byzantine artists employed 'reverse perspective' in which '[...] a painting of an altar, table, or throne will show both left and right sides' (Hockney and Gayford 2014: 85). He adds, 'reverse perspective is 
more about you' (2014: 85). There is opportunity for this painterly immersivity and distinctive point of view to return to CVR some centuries later, providing new 'screen ideas' for CVR media that have an awareness of historical regimes of vision: both the dominance of linear perspective and strategies which have challenged this to break-down the 'window on the world' paradigm. In this context, the storytelling concerns of CVR producers and critics are not precluded but they can be situated within a richer consideration of CVR's possible visual regime, as well as the 'reality' it attempts to represent.

\section{Artists' moving image}

Pushing the boundaries of both the visual regime and interactive components exterior to the spherical view is Carne y Arena (2017) which Iñárritu describes as 'whatever this medium is, it's another kind of film' (Thompson 2017). Carne y Arena is a short CVR work based upon real world accounts of immigrants and refugees who have crossed the border from Mexico to the United States in perilous circumstances. Iñárritu wrote his scenario based on a collaborative process of authorship derived from theatre-based workshops which produced dramatic re-enactments, a process he labels 'semifictionalised ethnography’ (Thompson 2017). For its Cannes iteration, Iñárritu installed his CVR work in a 'black-box' warehouse replete with real sand underfoot to simulate the desert experience and other immersive production design elements. He adds, 'if people come here with idea to see a short film, it's wrong [...] It's like taking two hours to go to the Biennale in Venice' (Thompson 2017). And, post-Cannes, Carne y Arena has 
been installed at the Prada Foundation (Milan) and Los Angeles County Museum of Art (LACMA) - the former being a key financier of the work.

With Carne y Arena, Iñárritu enters the domain of 'Artists' moving image' practice where the exterior of the frame (or lack of) is as important as the image itself. For art curator Chrissie Iles the 'spatial issues of video and film installation' (since the 1960s) have evolved in three distinct phases: phenomenological and performative; the sculptural and 'the cinematic' (2000: 252). The first phase includes the 'Expanded Cinema' of Gene Youngblood and the intermedia environments of the late 1960s and 1970s in which 'the participant [is turned] inward upon himself, providing a matrix for psychic exploration, perceptual and sensorial awareness [...]' (Youngblood 1970 in Iles 2000: 253). Andy Warhol's intermedia collaborations with the Velvet Underground provide another example of psychedelic immersivity between space and image. In this context, architectonic solutions are at once both space (enclosure) and surface (image) - a relationship amplified in Stan Van Der Beek's experimental Movie Drome theatre from the mid-1960s.

In the 1990s the 'cinematic' moving image leapt from the theatrical environment to the art gallery finding form with the production of large-scale cinematic, multi-screen moving image works. For Iles, content becomes space and space content, confronting a new audience 'by surrounding them with images and sound rather than physical walls' (2000: 253). Isaac Julien's Ten Thousand Waves (2010) produced a cinematic and immersive installation using nine double-sided screen projections within the space of the art gallery. More recently, Julian Rosefeldt's Manifesto (2015) delivered a similar image- 
space experience using thirteen screens offering cinematic moving images (and sound) projected on the walls and surfaces of the contemporary art gallery. For Iles, these works possess a rich late twentieth-century lineage: the work of Dan Flavin, which conflates 'gallery space with gallery time', and the durational screen works of Peter Campus (Iles 2000: 258). In an Australian context, the contemporary artist Shaun Gladwell has transferred this concept to virtual reality media with Reverse Readymade (2016) and Orbital Vanitas for Sundance 2016. Reverse Readymade reinvents - and inverts - Marcel Duchamp's Bicycle Wheel (1913) as Gladwell rides this 'readymade' bike in a 360degree loop around the VR camera rig/idealized viewer (Holsworth 2016).

Figure 3: Shaun Gladwell, Reverse Readymade, 2016. Courtesy of the artist and Anna Schwartz Gallery.

From the Renaissance to contemporary art, the interaction between screen/surface and spatiality presents a valuable field of images, and installation projects, from which to think, develop and theorize CVR and tactics to generate immersive screen ideas. However, with attention focused on the visual, there remains the uneasy question of how screenwriting might participate, and how it can incorporate these spatially diverse practices rather than become subsumed in separate conversations around storytelling. In particular, how to avoid limiting CVR screenwriting practice to mere translation of cinema's sovereign script to the new medium? 


\section{A new model for writing}

Maintaining the historicizing approach, these questions can be fruitfully worked through in relation to a polyphonic history of screen documents (Horne 1992), as well as Kathryn Millard's call to engage screenwriters in production rather than as auxiliary creatives (2016). The potential, as well as the challenge, is to find a model that allows the screenwriting process to be employed in multifaceted ways but with a rigorous approach to understanding how the new spatiality/design configuration of spherical vision can provide new forms of visuality. For the screenwriter, the ability to work with these processes requires intimate knowledge of the different production elements unique to CVR. At the same time, there is also value in recognizing that there is no inherent, 'correct' way to undertake this process. In the same way that Steven Price outlines the variety of, often overlapping, terms applied to stages of cinematic screenwriting (photoplay, synopsis, scenario, continuity, treatment, screenplay, working script, shooting script) that point to the difficulty of assuming one model from initial idea to screen, he also suggests that 'another way of conceiving the relationship, however, is to see these forms as representing a palette of options that a writer or writers may bring together in different combinations' (Price 2013: 18). The aim, then, is not to provide another 'howto' manual but rather suggest frameworks and working concepts that may be drawn upon and adapted. Kath Dooley (2017) has already noted some particular frameworks: the platform(s) on which the work will ultimately be viewed, noting the different spectatorship likely to occur between, for example, the low-end Google Cardboard viewer and the high end HTC Vive; the length of time that viewers can reasonably wear the current generation of headsets; the need to allow viewers to acclimatize to the new 
visual environments; and how the viewer's attention can be attracted and directed without the framing techniques available in other media. Additional to these concerns, though, is an urgent need to consider how to write, on the page, for spherically spatialized action; an aspect that has not yet received much attention. Although gaming provides precedents for narrative design in spatialized action and its development in VR can likely provide fruitful ways of considering its relevance for the CVR screenplay, the current lack of interactive components in CVR means that our focus here will be on how other noninteractive screenplay formats can be adapted for CVR.

With regards to the use of the page as starting point for screen production, the Master Scene format with its pared-down information, sitting amongst a writing workflow from synopsis to treatment to shooting script, has come to dominate and, in turn, governs the expectation that screenwriters begin with a conceptual realization of story that will only later be augmented by technical elements such as audio, camera shots and mise en scène. However, according to Julie Stone Peters, the history of play texts in the West, reaching back to the wide dissemination of theatrical texts in Europe in the sixteenth century demonstrates that there has long been a tension around what exactly should be included on the page and this was often in the context of a range of concerns such as the type of dramas that were favoured; intended audiences for the text (whether performers or merely interested readers); and artistic control (2011: 27). For example, there was a decrease in character and/or scenic description in the sixteenth century to reflect the move towards humanist dramas and away from fifteenth-century spectacles but it also reflected the uptake of these texts amongst ambulatory troupes and professional companies whose own practice restricted their use of these descriptions 
(Peters 2011: 27). Counteracting this in the nineteenth century, the competition with the novel, the increasingly elaborate spectacles and the surge of illustrated books led to elaborate visual information within play texts (Peters 2011: 83). However, according to Peters, mid-way through these periods, in the 1770 publication of Pierre Beaumarchais' The Two Friends, or the Merchant of Lyon, Beaumarchais provided specific instructions for blocking and textual specifications so that his dramatic vision would be replicated rather than adapted (Peters 2011: 258). In the history of screenwriting, accounts of the consolidation of the continuity script into the master scene, even with debate around whether this happened in the 1930s or 1950s, often suggest a unified formalization of screenwriting practice and how the page appeared (Bordwell et al. 1985; Sternberg 1997). However, Price's (2013) discussions of variations happening in Europe, as well as the back and forth between the different types of information written on to the page in Hollywood, and the continuation of alternative modes in texts for documentary, articulate the manifold ways in which screenwriting has responded to the task of providing filmmakers with a textual beginning for the film.

Significant to this discussion, is the extent to which the design of the page, and other material provided alongside, is not simply a question of how much technical information is provided prior to the shooting script/theatrical prompt book that is taken into production. Instead, this information has its own organizational impact that can interact with and influence the visual regime initiated by the text. Peters points to this in her description of the relationship between seventeenth-century illustrations accompanying play texts and the perspectival arrangement that framed the way the 'centralizing politics of the period' appeared onstage: 
Whether the proliferation of illustrations in itself helped to reshape scenic design, it is clear that there was an important reciprocity between stage design and page design. Framed stage settings (stage 'frontispieces') and architecturally framed title pages (book 'frontispieces') mirrored each other. The space of the decorative page (delimited and ringed in ornamental borders) helped to model the framed and unified space of the scene: theoretically fixed in time; representing a translation of temporal unity into space; ideally protected from audience incursion, aesthetically untouchable and apart. (Peters 2011: 191)

On the one hand, the Master Scene format's eschewal of a lack of detailed illustrative elements - mainly writing out a temporal unfolding of action descriptors, dialogue and indicators of the locations in which action will takes place - suggests that the story (including its particular plot devices) has a singular existence that can be adapted to different visual permutations and thus does not dictate any particular visual regime. On the other hand, it lends itself to the repetition of conventional screen organization rather than addresses how new visual organization might come into play. In this context, a model for CVR writing that considers how the page can reflect new spatialization so that it can be integrated as a key component of narrative, action and character relations is a return to prior methods of working rather than a deviation from accepted screen writing practice. 
Figure 4: Page from Ian Tuason's example CVR screenplay, 3am (2015), Dimension Gate.

Figure 5: Page from Sprott Woods' example CVR screenplay (2016).

Figure 6: Page from Elia Petridis and Devin Embil's screenplay for Eye for an Eye (2016), Filmatics.

This practice has already been taken up by CVR practitioners such as Ian Tuason (Figure 4), Sprott Woods (Figure 5), Elia Petridis and Devin Embil (Figure 6), who illustrate different approaches to writing and designing spatial elements into the screenplay but with various commonalities. Although none make clear whether the texts they provide as examples are a type of shooting script that has been preceded by a more traditional master scene, they offer a way of visualizing scenes that takes into account 360 -degree space and follow Iñárritu's provocation that VR should find ways to 'break the dictatorship of the frame' (cited in Los Angeles County Museum of Art [LACMA] 2017). In particular, each divides space into four quadrants that need to be taken into account when considering the elements that will be engaged within the scene. Miriam Ross' practice-based research in this area diverged slightly during the shift from the use of a traditional Master Scene format on an initial CVR production Until Jesse 360 (2018, made in collaboration with Henry Bennison) to Ross' current work-in-progress piece Embodied. In the latter, space is not divided into four quadrants but, nonetheless, a 
diagrammatic birds-eye view on each page, illustrating the space to be filmed, acts as a reminder of the absence of a frame (Figures 7 and 8). It relates to textual description and space for dialogue at the top of the page but also to artwork at the bottom of the page, whose inclusion is to avoid separation into a distinct storyboard, where the organizational tendencies of the storyboard tend towards perspectival viewing in which the viewer is positioned outside the frame. Here, the traditional representations of screenwriting and creative pre-production are fused so that the CVR screenplay becomes a hybrid document, which is part-script, part-storyboard and part-shot list. This prompts the question of the legibility of the CVR screenplay with this degree of spatialized and technical information overlaid on the page. One of the enduring features of the Master Scene format has been its readability - particularly in relation to the needs of development and financing. This suggests an interesting trajectory of this research to be further examined: to what extent should readability be promoted at the expense of clearly defining the spatial qualities essential to CVR and vice versa?

With respect to audio elements, these are given equal weight within this schema rather than folded into the description and dialogue with the aim to consider its 360 degree spatialization as a determining component rather than support for other elements. This is not the first time that audio has had its role amplified on the page - and Price (2013) provides examples dating back to the introduction of 'talkies' - but, in the same way that audio was emphasized when new technological manifestations were being worked through, there is value in doing the same now that ambisonic microphones (which record audio from every direction) are becoming the norm for 360-degree media capture with the directional input of audio is playing a more predominant role. The 
context for Ross's practice-based research is also significant here as CVR production takes place within the academy, produced with limited financial resources and outside of the conventional film roles associated with industrialized film production. That is, the CVR screenplays for this work are designed for small-scale production that subsumes the traditional roles of screenwriter, storyboard artist, director, production designer, cinematographer and sound recordist. This research aims to invigorate the discussion around collaborative practices involved in CVR and contribute to the development and articulation of the parameters which are outlined by screen agencies and funding bodies. For example, in an Australian context current VR funding schemes divide the roles of 'Artist' and 'VR practitioner' which stands in contrast to the more integrated approach suggested by the models of practice-based research framed in this article (Create NSW 2017).

Figure 7: Page from Miriam Ross's screenplay for Embodied (in progress).

Figure 8: Page from Miriam Ross's screenplay for Embodied (in progress).

Within the diagrammatic approach, Ross's primary aim is to foreground the position of the camera throughout the scene so that it is not merely a case of what the camera can see (360-degrees), but where it is positioned in space and what type of relationships will be produced between the characters and performative actions that also occupy this space. While it might seem egocentric and anti-democratic to give such predominance to the camera/viewer, in many ways enforcing the Age of Enlightenment ideals of a subject- 
viewer position that has mastery of the scene in front of them (Marks 2000), there is a distinct inflection to this within the enhanced embodiment paradigm provided by the VR viewpoint. In the same way that the stereoscopic viewpoint in nineteenth-century photography counteracted the camera obscura/renaissance perspective model of an observer outside of the framed scene (Crary 1992; Schröter 2014), the central position of the viewer in 360 space, often coupled with stereoscopic visuality, means an embodied, within, position. While an immediate immersion within the scene is often overemphasized in discussion of VR, this centralized positioning does have an impact on the way the viewer can relate to characters around them and how these relations might be written into the screenplay. Within this context, though, the centrality of the viewer/camera should not be taken to mean that the viewer/camera must always be placed within the centre of space. In some ways, the quadrant approaches in the aforementioned screenplays tend towards that position. Even though the resulting CVR experiences might differ - as is the case in Eye for an Eye (2016) by Elia Petridis and Devin Embil where the camera is positioned towards the corner of a spacious open plan living space - the quadrant approach suggests that each 'side' of the camera should be equally filled. In contrast, Ross's approach takes into account visual schemata such as the golden ratio/Fibonacci spiral to think about how an off-centre position can be judicially (rather than dogmatically) applied to CVR. The diagrammatic approach on the page aids this aspect by making it possible to scan quickly through the entire screenplay in order to determine where there is repetition (or not) of spatial configurations; how to make sure any patterns are purposefully implemented; and where they leave characters and their actions in the space. 
One of the benefits of this visualization is a consideration of how 'dead' space might be effectively utilized. Even the most descriptive location settings within the Master Scene tend towards outlining what can be seen, with any restrictions used for distinct narrative purpose. In the early wave of CVR works, the expanded possibilities offered by the absence of the frame reduce inclinations to put in place restrictions even further; filling all angles of 360-degree space is deemed somewhat necessary in order to warrant the use of the frame-less filming technology. At the same time, this drive towards fully using what the technology can offer as well as finding a balance with other concerns has already been played out in other expansive visual media. In the history of 3D cinema there have often been expectations that the ability to push objects into auditorium (negative parallax) space or allow them to retreat behind the screen (in positive parallax space) will mean this mode predominates. However, in most commercial 3D releases there is a flux between overt use of negative/parallax space and shots that are almost as flat as 2D images. Experienced stereographers write this into their version of the shooting script, producing graphs that map depth budgets to show how extensively negative and parallax space will or will not be used (Figure 9). At times, the depth budget is used to highlight how 3D space can augment particularly emotive moments or those of narrative concern while at other times it is used to produce interesting and affective rhythms throughout the entirety of the film (Ross 2015; Yong forthcoming). In CVR, the frame will never be reconstituted in the same way that the 3D film can become 'flat' but there can be a similar flux between the use of full 360-degree space and more contained fields of view. For example, positioning the camera in close proximity to a wall, door or other hard surface creates space that is unlikely to be looked at, 'dead', and without the 
possibility of action. Again, the use of diagrammatic visualization in the CVR screenplay, with its emphasis on where the camera is situated in centred or off-centred positions, can help track the way restrictions can be imaginatively integrated in individual shots as well as how rhythms between extended and constrained views can be used in conjunction with narrative across the entirety of the screenplay.

Figure 9: A depth script for a 3D feature film (copyright Brian Gardner).

This visual mapping of space on the page also takes into account the proximity CVR has with computer game environments, be they in VR or not, whereby players/viewers are encouraged towards multi-directional visual exploration. As noted by Henry Jenkins, this is not solely a feature of game mechanics but, rather, 'the core narrative behind many games centre around the struggle to explore, map and master contested spaces' (2004: 122). While prior expansive visual technologies such as stereoscopy and $3 \mathrm{D}$ cinema have undertaken this exploration within colonial systems of the gaze (Bennet 2013; Gurevitch 2012), attention to these contexts can allow current screenwriters to think about how mapping, exploration and the multidirectional possibilities of the gaze can be addressed on the page in a way that interrogates rather than inherently replicates past uses of expansive space. For example, the screenplay for Embodied attempts to articulate the camera/viewer as always in relation to another human subject within space, sharing aspects of their subjective engagement with it so that a 'mastery' gaze is mitigated through reciprocity. 
To date Ross's research has been working with the limits of the flat page, thinking through how the articulation of a single scene or shot might speak to the various spatial elements (including audio) that need to be addressed in 360-degree filmmaking. In digital filmmaking work has already been undertaken to provide tools for spatial 'pre-

visualisation' (or pre-viz), generated within parametric animation software to map scenes for production. George Lucas is one who has explored new modes of scripting - he likens this mode of development to 'the process of a painter or sculptor' (Kelly and Parisi 1997: 162 in Maras 2009: 182). The potential to inhabit three-dimensional (virtual space) within the screenplay as opposed to representing it on the page in manuscript form has implications for extending further the screenwriter's ability to contribute to a dynamic spatial environment and take into account the same type of design considerations that play a role in gallery installations, as discussed earlier in this article, or expanded screen scenarios.

\section{Conclusion}

This article has drawn upon current research into CVR in order to articulate new forces on the screenplay, and screenwriting practices, for emerging media. With digital disruption the separation between screenwriting and production, already dismantled in the era of digital filmmaking, is likely to narrow further. The consequences are evident in the need for spatialized, and hybridized, screenplay forms nestled within more iterative models of production often drawn from processes more associated in relation to the fields of design and the creative industries. In this context, the evolution of the CVR screenplay can look beyond the Master Scene format/continuity script/sovereign script, towards 
more generative possibilities as a spatialized text, whilst maintaining the possibility of being part of a screenplay in production rather than final draft (Munt 2008; Maras 2009; Millard 2014). This offers the possibility to explore digitised models of scripting for CVR and the provision of convergent screenplay models that work across new digital platforms. This article suggests that a consideration of CVR screenplay prototypes and practices for emerging media will benefit from an eclectic (re)appraisal of historical modes of image-making drawn from the visual arts, early cinema, expanded cinema, artist's moving image practices and stereoscopic cinema. The emphasis towards practicebased research in the later part of this article confirms the value for CVR production as a space to interrogate, and innovate, the spatialized screenplay. This aligns with the trend in digital cinema in situating the screenplay within production. It also reveals the academy as a dynamic site for CVR production-based research, in the infancy of a medium, fuelled by affordable technologies and open models of practice which are yet to be industrialized. That is, academic research in this field has the potential to circumvent the 'straitjacket' of prescribed mainstream screenwriting, within which our screen industries will struggle to innovate. The development and execution of engaging screen ideas for emerging media will be located between these two poles, to benefit from an awareness of historicallybased image-making practices and the ability to test the efficacy of spatialized screenplay templates designed for emerging media.

\section{References}

$3 a m$ (2015), Dir: Ian Tuason, Canada: Dimension Gate, 3:03 mins. 
AFTRS/Start VR (2016), VR Noir, Sydney: AFTRS/Start VR.

Bennet, B. (2013), 'The normativity of 3D: Cinematic journeys, "Imperial Visuality" and unchained cameras', Jump Cut, 55, pp.1-23.

Bordwell, D., Thompson, K. and Staiger, J. (1985), The Classical Hollywood Cinema: Film Style and Mode of Production to 1960, London: Routledge.

Bucher, J. K. (2017), Storytelling for Virtual Reality: Methods and Principles for Crafting Immersive Narratives, New York: Routledge.

Carne y Arena (Flesh \& Sand) (2017), Wr/Dir:Alejandro González Iñárritu, USA, 7 mins.

Cavazza, M. (2007), Virtual Storytelling: Using Virtual Reality Technologies for Storytelling: 4th International Conference, ICVS 2007, Saint-Malo, France, December 5-7, 2007, Proceedings, Dordrecht: Springer (lecture notes in computer science, vol. 4871).

Crary, J. (1992), Techniques of the Observer: On Vision and Modernity in the 19th Century, Cambridge, MA: MIT Press. 
Create NSW (2017), '360 vision: Virtual reality development initiative for the arts 2017’, https://www.create.nsw.gov.au/funding-and-support/types-of-funding/360-vision-virtualreality-development-initiative-arts-2017/. Accessed 7 May 2018.

Collisions (2016), Wr/Dir: Lynette Walworth, Australia, 17 mins.

Dooley, K. (2017), 'Storytelling with virtual reality in 360-degrees: A new screen grammar', Studies in Australasian Cinema, 11:3, pp 161-71.

Embodied (forthcoming), Wr/Dir: Miriam Ross, New Zealand.

Eye for an Eye (2016), Wr/Dir: Elia Petridis, USA, 11 mins.

Google Creative Lab and NASA (2017), Access Mars, Google Creative Lab and NASA, California, USA.

Grambart, S. (2015), 'Sleepy hollow \& narrative in VR (slide share)', 10 December, https://www.slideshare.net/fitc slideshare/sleepy-hollow-narrative-in-vr. Accessed 13 December 2017.

Gunning, T. (1990), 'The cinema of attractions: Early film, its spectator and the avantgarde', in T. Elsaesser and A. Barker (eds), Early Cinema: Space-Frame-Narrative, London: BFI Publishing, pp. 57-62. 
Gurevitch, L. (2012), 'The birth of a stereoscopic nation: Hollywood, digital empire and the cybernetic attraction', Animation, 7:3, pp. 239-58.

Hockney, D. and Gayford, M. (2014), A History of Pictures: From the Cave to the Computer Screen, London: Thames \& Hudson.

Holsworth, M. (2016), 'Gladwell's reversed readymade', Melbourne Art Critic.com, Accessed 21 December 2017.

Horne, W. (1992), 'See shooting script: Reflections on the ontology of the screenplay', Literature/Film Quarterly, 20:1, pp. 48-54.

Iles, C. (2000), 'Video and film space', in Erika Suderburg (ed.), Space, Site, Intervention: Situating Installation Art, Minneapolis: University of Minnesota Press, pp. $252-62$.

Invisible (2017), Dir: Doug Liman, USA, 6 mins x 5 eps.

Jenkins, H. (2004), 'Game design as narrative architecture', in N. Wardrip-Fruin and P. Harrigan (eds), First Person: New Media as Story, Performance, Game, Cambridge: MIT Press, pp. 118-30. 
Jerald, J. (2015), The VR Book: Human-Centered Design for Virtual Reality, San Rafael, CA: Morgan \& Claypool.

Kelly, K. and Parisi, P. (1997), 'Beyond Star Wars', Wired, https://www.wired.com/1997/02/fflucas/. Accessed 20 May 2018.

Los Angeles County Museum of Art (LACMA) (2017), 'Alejandro G. Iñárritu: CARNE y ARENA' ('Virtually Present, Physically Invisible'), LACMA, http://www.lacma.org/carne-y-arena\#about-the-exhibition. Accessed 15 December 2017.

Lowis, K. and Pickeral, T. (2016), 50 Paintings You Should Know, Munich: Prestel.

Macdonald, I. W. (2013), Screenwriting Poetics and the Screen Idea, Palgrave Studies in Screenwriting, Basingstoke: Palgrave Macmillan.

Maras, Steven (2009), Screenwriting: History, Theory \& Practice, London: Wallflower Press.

Marks, L. U. (2000), The Skin of the Film, Durham: Duke University Press.

Mateer, J. (2017), 'Directing for cinematic virtual reality: How the traditional film director's craft applies to immersive environments and notions of presence', Journal of Media Practice, 18:1, pp. 14-25. 
Millard, K. (2006), 'Writing for the screen: Beyond the gospel of story', SCAN: Journal of Media Arts Culture, 3:2, http://scan.net.au/scan/journal/display.php?journal id=77. Accessed 13 December 2017. (2014), Screenwriting in a Digital Era, Palgrave Studies in Screenwriting, Basingstoke: Palgrave Macmillan. (2016), 'The universe is expanding', Journal of Screenwriting, 7:3, pp. 271-84.

Munt, A. (2008), 'Am I crazy to make a film for $\$ 100,000$ or crazy not to? Kriv Stenders goes Micro Budget Digital for Boxing Day', Senses of Cinema, 46, http://sensesofcinema.com/2008/australian-cinema-46/kriv-stenders-boxing-day/. Accessed 21 December 2017.

The Next Striker (2017), Tom Phillips, Jumpgate VR, 2-4 mins, 7 eps.

Panofsky, E. (1991), Perspective as Symbolic Form, Cambridge, MA: Zone Books.

Paoletti, J. T. and Radke, G. M. (1997), Art in Renaissance Italy, New Jersey: Prentice Hall. 
Peters, J. S. (2011), Theatre of the Book 1480-1880: Print, Text and Performance in Europe, Oxford: Oxford University Press.

Price, S. (2013), A History of the Screenplay, Basingstoke: Palgrave Macmillan.

The Protectors (2016), Wr/Dir: Kathryn Bigelow, USA, 8 mins.

Reverse Readymade (2016), Dir: Shaun Gladwell, Australia, 11 mins.

Ross, M. (2015), 3D Cinema: Optical Illusions and Tactile Experiences, Basingstoke: Palgrave Macmillan.

Schröter, J. (2014), 3D: History, Theory and Aesthetics of the Transplane Image, New York: Continuum Publishing Corporation.

Shark Dive VR (2016), Australia, 2 mins.

Sinisgalli, R. (2011), Leon Battista Alberti: On Painting : A New Translation and Critical Edition, New York: Cambridge University Press.

Sternberg, C. (1997), Written for the Screen, Tübingen: Stauffenburg Verlag. 
Syed, R. (2017), ‘Gaze, Circle v Square’, http://circlevsquare.xyz/. Accessed 15

December 2017.

Taxi Driver (1976), Wr. Paul Schrader, Dir. Martin Scorsese; USA, 114 mins.

Thompson, A. (2017), 'Why Alejandro González Iñárritu is the director who finally got VR right - Cannes 2017’, IndieWire, 20 May, http://www.indiewire.com/2017/05/alejandro-gonzalez-inarritu-carne-y-arena-cannes-vr1201819096/. Accessed 13 December 2017.

Tricart, Celine (2017), Virtual Reality Filmmaking: Techniques \& Best Practices for VR Filmmakers, New York and London: Routledge.

Turvey, G. (2004), 'Panoramas, parades and the picturesque: The aesthetics of British actuality films, 1895-1901', Film History, 16:1, pp. 9-27.

Unimersiv (2015), VR Dinos, France: Unimersiv.

Until Jesse 360 (2018), Wr/Dir: Miriam Ross (in collaboration with Henry Bennison), New Zealand, 5 mins. 
Woods, S. (2016), 'Formatting a script for VR', Sprott Woods, https://www.sprottwoods.com/virtualreality/2018/4/17/formatting-a-script-for-vr. Accessed 8 May 2018.

Yong, Lui (forthcoming), 3D Cinematic Aesthetics and Storytelling, London: Palgrave Macmillan.

Youngblood, G. (1970), Expanded Cinema, New York: Dutton.

\section{Contributor details}

Dr Miriam Ross is Senior Lecturer in the Film Programme at Victoria University of Wellington. She works with new technologies to combine practice-based methods and traditional academic analysis. She is the author of South American Cinematic Culture: Policy, Production, Distribution and Exhibition (2010) and 3D Cinema: Optical Illusions and Tactile Experiences (2015) as well as publications and creative works relating to film industries, mobile media, virtual reality, stereoscopic media and film festivals.

\section{Contact:}

Victoria University of Wellington, New Zealand/Aotearoa

E-mail: miriam.ross@vuw.ac.nz 
Dr. Alex Munt is a screenwriter, director and visual artist working across narrative cinema, moving image, photography and immersive media. His current research interests include screenwriting, artists' moving image practices and cinematic virtual reality. Alex is a Senior Lecturer in Media Arts \& Production in the School of Communication, Faculty of Arts \& Social Sciences at the University of Technology Sydney.

\section{Contact:}

University of Technology Sydney (UTS), Sydney, Australia

E-mail: alex.munt@uts.edu.au 